\title{
EL ESTUDIO DE LA HISTORIA ECONOMICA EN HOLANDA
}

\author{
P. W. KLEIN \\ Erasmus Universiteit Rotterdam
}

\section{Introducción}

Lo primero que sorprende al aproximarnos a la historia económica de los Países Bajos, tomando un enfoque cuantitativista - hoy casi un hábito entre los historiadores económicos-, es su participación relativamente elevada en el quehacer histórico. Las cifras pueden ser extraídas grosso modo del Repertorium oficial publicado bajo los auspicios del Comité Estatal de Historia Nacional, ya que este registro incluye los escritos sobre historia holandesa realizados por extranjeros, mientras excluye el trabajo de historiadores holandeses sobre otros países ${ }^{1}$. Entre 1979 y 1982 se registró una media anual de aproximadamente 4.200 títulos de libros y artículos sobre historia holandesa; la media anual en los campos de historia económica y social fue de 680 títulos, es decir, de un 16 por 100 . En realidad, las cifras reales pueden haber sido muy superiores, dado que numerosos libros y artículos incluidos en otros apartados, y especialmente bajo la denominación de Historia de Ultramar, se ocupan de temas de historia económica propiamente dicha. Hay que tener en cuenta que no hay persona que por sí sola esté en situación tal que le permita controlar un flujo casi constante de dos publicaciones diarias con garantía de certeza absoluta. Cualquier juicio general sobre la calidad del trabajo producido puede ser discutido, ya que tiene necesariamente que basarse en evidencia incompleta.

De ahí que en estas páginas me imponga explícitamente una serie de severos límites y restricciones. A pesar de ello, la validez de mis argumentos es limitada y no pueden ser considerados más que en un plano meramente introductorio. Dejando completamente al margen la Historia social, empezaré por un breve examen de los orígenes de la Historia económica como rama más o menos especializada dentro de la investigación histórica. Luego me referiré a sus etapas más tempranas y a sus peculiaridades hasta finales de los años

' Th. S. H. Bos $(1981,1982,1983,1984)$. Para un resumen de la historiografía holandesa: Acta Historiae Neerlandicae (Estudios sobre la Historia de los Países Bajos). 
cincuenta de este siglo, aproximadamente. De ahí pasaré a estudiar su crecimiento y desarrollo como disciplina durante el último cuarto de siglo, aproximadamente. Intentaré demostrar cómo la tendencia dominante durantc este período se alejaba de la descripción puramente verbal de los hechos y se inclinaba hacia su explicación teórica y hacia el análisis cuantitativo. Finalmente, intentaré señalar algunos de los principales temas de debate durante estos años. sin tener en cuenta, no obstante, la historia económica medieval. Fsto no quicre decir que no se haya hecho ninguna aportación de importancia en esta rama historiográfica, muy al contrario. B. H. Slicher van Bath, quizá el más conocido de los historiadores económicos holandeses, ha sido un autor pionero y muy prolífico en el terreno de la historia económica de los Países Bajos durante la Edad Media. Sus estudios incluyen temas tan ambiciosos en su perspectiva como es el comercio «internacional" de Friesland en un momento en que la Europa continental caía víctima del estancamiento y del cambio demográfico en las zonas orientales del país ${ }^{2}$. Otros historiadores que deben ser mencionados en este contexto son D. E. H. Boer (demografía), C. Dekker (patrones de asentamiento/reclamación de tierras), J. C. G. M. Jansen (tendencias económicas a largo plazo), H. P. H. Jansen (comercio, navegación), T. S. Jansma (comercio), W. Jappe Alberts (historia urbana, asuntos fiscales). $H$. van der Linden (derechos de propiedad, reclamación de tierras) y J. F. Niermever (historia de las instituciones). El lector interesado puede consultar para mayor información los libros de texto de J. A. van Houtte ${ }^{3}$, W. lappe Alberts y H. P. H. Jansen ${ }^{4}$, y J. H. van Stuijvenberg ${ }^{5}$. Los capítulos correspondientes a la Algemene Geschiedenis der Nederlanden tienen también información útil ${ }^{\circ}$.

Resumiendo las principales conclusiones de estas amplias y extensas investigaciones sobre historia económica medieval, se puede afirmar con bastante seguridad que el sistema feudal nunca llegó a arraigar en profundidad. Comercio y dinero estuvieron siempre presentes de una u otra forma; la propiedad individual dio lugar a una economía agrícola progresiva y la organización de la sociedad rural se caracterizó por la especialización y la diferenciación a partir de los siglos XI y XII, aproximadamente. El sistema de vida tradicional fue progresivamente desarraigado por un proceso de urbanización más o menos continuo. En un principio, el centro de la actividad económica gravitaba en torno a los principales ríos, situados en el centro y Este del país. Desde mediados del siglo XII, sin embargo, el centro se desplazó hacia las regiones marítimas del

: B. H. Slicher van Bath (1945 y 1965$)$.

3 J. A. van Houtte (1977).

4. Jappe Alberts/H. P. H. Jansen (1964).

R. van Uytven (1978). 1982).

- Algemene geschiedenis der Nederlanden. Middelceuwen, vols. I.IV (1980, 1981, 
Oeste, a las provincias de Holanda y Zelandia. Ya en fecha tan temprana, el movimiento indicaba claramente las líneas maestras del desarrollo económico que tendría lugar a comienzos de la Edad Moderna, e incluso apuntaba aquellas de la era industrial.

\section{Los comienzos}

Pudiera parecer que la historia económica en los Paises Bajos ha tardado en desarrollarse, lo que resulta sorprendente teniendo en cuenta, al menos, dos consideraciones. En primer lugar, la importancia de la historia económica - hija adoptiva de la economía ${ }^{7}$ - como campo de investigación ya había sido reconocida por Adam Smith. Los aspectos teóricos de la obra de Smith pronto encontraron amplia aceptación en Holanda, pero no así su interés por los estudios históricos. Ni siquiera en Inglaterra tuvieron interés por la Historia sus más inmediatos sucesores, por lo que no se puede culpar excesivamente a los investigadores holandeses por no haber recogido el hilo. Tampoco hubo respuesta directa o reacción alguna por parte de los holandeses cuando los pre cursores de la Escuela Histórica, en Alemania, y Karl Marx iniciaron su levantamiento contra la aproximación atemporal a los temas humanos de los economistas clásicos, durante la década de los años 1840. La influencia de estos últimos no se hizo sentir hasta en torno a 1900, a través de las enseñanzas de individuos tales como M. W. F. Treub, quien se convirtió, junto con D. van Emden, en un importante hombre de Estado, siendo ambos profesores en la Facultad de Derecho de la Universidad de Amsterdam.

En segundo lugar, la falta de interés de los holandeses resulta más sorprendente a la vista de sus espectaculares logros pasados, en especial la importancia capital del comercio, la navegación y la iniciativa holandesa para la economía mundial. A pesar de ello, los conocimientos y la investigación sobre este fenómeno permanecieron esporádicos e incidentales a lo largo del siglo xix. Normalmente, los historiadores se contentaron con lamentar la pérdida de la edad dorada del siglo xvir y culpar, en general, el relajado modo de vida de sus antepasados durante el siglo xviII.

J. Scheltema escribió en 1817 sobre las relaciones comerciales entre holandeses y rusos; B. Blaupot ten Cate estudió historia marítima, y H. J. Koenen y H. C. Diferee fueron precursores en historia del comercio. Ni siquiera existía una denominación propia para estos estudios, por lo que los historiadores holandeses utilizaron simplemente el término alemán Wirtschaftsgeschichte. Por otra parte, algunas de las obras más importantes fueron escritas por historiadores alemanes. E. Laspeyres estudió las ideas y políticas económicas durante

\footnotetext{
' P. H. Winkelman (1978).
} 
el siglo xvir, y O. Nachod escribió un libro sobre las relaciones comerciales entre los holandeses y Japón durante la misma centuria. Incluso la primera obra de conjunto sobre la historia económica holandesa - que no apareció hasta 1927- fue escrita por un alemán, E. Baasch, lo cual es bastante revelador ${ }^{8}$.

¿Cuáles pudieron haber sido las razones de este tardío comienzo y lento desarrollo? Se podría pensar que las condiciones económicas existentes tuvieron algo que ver con ello. Aunque muchas de las ideas y opiniones anteriores sobre la economía holandesa durante el siglo XIX se consideran hoy equivocadas - tema sobre el que volveré más adelante-, el relativamente lento crecimiento de la economía, debido a la pervivencia de los patrones tradicionales agrícola-comerciales hasta mediados de siglo, sigue siendo un hecho. La modernización no se inició en serio hasta la década de los años 1860 , y la industria moderna no se abrió realmente camino hasta después de 1895 . Es difícil considerar mero accidente el hecho de que la primera generación de historiadores económicos holandeses -N. W. Posthumus, J. G. van Dillen y Z. W. Sneller- escribieran unas tesis doctorales que marcaron un hito a comienzos del siglo $\mathrm{xx}$, cuando la sociedad estaba, finalmente, transformándose a gran velocidad a través de un proceso de crecimiento económico moderno ${ }^{9}$.

\section{Desarrollo inicial ${ }^{10}$}

El status académico de la historia económica como disciplina no se confirmó hasta el establecimiento, en 1913, de la anterior Escuela Holandesa de Económicas - en la actualidad, la Universidad Erasmus, de Rotterdam-. Posthumus, que fue uno de sus dos primeros profesores, se convirtió también en el primero en detentar una cátedra en Historia económica, tan sólo tres años después de que George Unwin fuera llamado para la primera cátedra inglesa en Historia económica, en la Universidad de Manchester. Es difícil exagerar la importancia de Posthumus. Como investigador publicó gran cantidad de obras que son aún clásicos en la materia: sus estudios sobre las industrias textiles de Leiden y su trabajo sobre fuentes para la historia de los precios aún son utilizados ampliamente, e incluso a nivel internacional. Como organizador, tomó la iniciativa para el establecimiento de la Biblioteca y Archivos de Historia Económica, el Instituto Internacional de Historia Social y la Oficina Estatal para la Historia de la Segunda Guerra Mundial. Cuando fue nombrado profesor de Historia económica de la recién fundada Facultad de Eco-

*E. Baasch (1927).

N. W. Posthumus (1908); J. G. van Dillen (1914); Z. W. Sneller (1916).

10 Véanse: P. H. Winkelman (1978); W. J. Wieringa (1978); P. W. Klein (1970) en el apéndice; B. H. Slicher van Bath (1967); W. W. Minjnhardt (1983). 
nomía de la Universidad de Amsterdam, en 1923, Sneller se convirtió en su sucesor en Rotterdam.

Cuatro años más tarde, sin embargo, cuando se fundó la Escuela Católica Romana de Economía, en Tilburg, la Historia económica fue tan sólo incorporada a la cátedra de Historia moderna. Durante casi un cuarto de siglo, el desarrollo institucional de la profesión estuvo estancado, dado que no se volvieron a crear nuevas cátedras hasta después de la Segunda Guerra Mundial. Es de señalar que, en las Universidades, la Historia económica no encontró lugar como materia independiente vinculada a los distintos departamentos de Historia. Los estudiantes de Historia de Amsterdam tenían ocasión de asistir a las clases de Posthumus, y Sneller obtuvo un puesto de profesor especial en la Universidad de Leiden en 1939. Eso era todo. Mientras, historiadores económicos de la categoría de J. G. van Dillen, que no obtuvo el profesorado hasta 1949; H. J. Smit, J. C. Westerman y W. S. Unger tuvieron que ganarse la vida fuera de la Universidad. Durante la depresión de los años treinta, jóvenes y prometedores historiadores económicos, como I. J. Brugmans, T. S. Jansma, J. H. Kernkamp y C. Wiskerke, se tuvieron que enfrentar a una situación singularmente sombría. En estas circunstancias, no es de extrañar que la capacidad de irradiación de Posthumus y Sneller se viera muy limitada. Sus enseñanzas se dirigían a los estudiantes de ciencias económicas, por lo que sus discípulos, normalmente, se dedicaban a trabajar para la empresa privada o el Gobierno, incluso después de haber presentado sus tesis doctorales, y con todo lo notables que sus conocimientos pudieran ser. Uno de ellos, Th. L. M. Thurlings, que habría de ser profesor de Economía en la Escuela de Agricultura de Wageningen y presidente del Senado holandés, llegó a comentar, después de la guerra, que hasta entonces la historia económica había sido practicada, sobre todo, por aficionados ". Como lector en Historia económica en la Escuela de Económicas de Holanda, en 1947, se justifica que llamara la atención sobre la falta de conocimientos teóricos de los historiadores económicos holandeses. Esta queja, sin embargo, era algo injusta según las condiciones generales en que se encontraba la disciplina, tanto a nivel nacional como a nivel internacional.

Durante el período de entreguerras, la historiografía económica holandesa se puso al corriente de las tendencias internacionales de esta disciplina. La influencia de la Escuela Histórica Alemana fue desvaneciéndose, mientras los métodos analíticos británicos y norteamericanos se fueron imponiendo. Así se prestó especial atención al estudio de los ciclos económicos y a la descripción completa del comercio, la navegación, las finanzas, la agricultura, la industria, la política económica y los sistemas e instituciones económicos, siempre en

"Th. L. M. Thurlings (1947). 
continuo cambio. Aún no existía, sin embargo, la idea de que la economía en su conjunto podía ser considerada un sistema de variables interdependientes. Así, pues, los fenómenos económicos eran considerados como unidades más o menos autónomas y autosuficientes o sectores que se podían estudiar de forma primordialmente descriptiva y apenas explicativa.

Este enfoque no cambió realmente hasta finales de los años cincuenta. No obstante, algunos cambios importantes se iniciaron en los años de la posguerra y continuaron hasta bien entrados los años sesenta, y fueron, finalmente, detenidos por los problemas financieros de los años setenta y ochenta. Merece la pena señalar tres líneas bien diferenciadas, pero relacionadas entre sí.

\section{Crecimiento y desarrollo}

En primer lugar, ha habido un aumento sustancial en el número de historiadores económicos profesionales y no profesionales, de menos de 20 personas, probablemente, en los años cuarenta a, quizá, 150 ó 200 estudiosos en nuestros días. En segundo lugar, la Historia económica ha sido, finalmente, reconocida como una rama especializada de los estudios históricos, lo que atestigua el establecimiento de puestos para la enseñanza de esta materia en todos los departamentos de Historia de las Universidades. Después de haberse abierto la posibilidad de tomar cursos de Historia económica a los estudiantes de Historia, a finales de los años cincuenta, esta materia se incorporó, finalmente, como obligatoria en los años sesenta. El número de cátedras en las Facultades de Economía y en las de Ciencias Sociales, cuyo número también aumentó considerablemente en estos años, se multiplicó. Además de esto, se adscribió a estas cátedras, en las que los profesores habían trabajado en completo aislamiento con anterioridad, un cuerpo sustancial de personal más joven. Finalmente, la organización académica dio lugar a una creciente diferenciación entre Historia económica e Historia social, como indica el establecimiento de cátedras separadas para cada rama. Manuales y obras de consulta por autores holandeses, tan escasos con anterioridad, empezaron a salir a la luz pública en los años sesenta. Aparte de los ya mencionados, merecen ser citados los siguientes: I. J. Brugmans, Van Paardenkracht en Mensenmacht (1961), que cubre el período 1795-1940; J. G. van Dillen, Van Rijkdom en Regenten (1970), que trata de la República holandesa; Joh. de Vries, The Netherlands economy in the twentieth century (1978); P. A. M. Geurts, F. A. M. Messing (eds.), Theoretische en methodologische aspecten van de economiscbe en sociale geschiedenis, I, II (1978, 1979).

A la vista de este crecimiento y desarrollo, no es sorprendente que el estudio de la Historia económica también se haya visto sujeto a un proceso de innovación. 
Esta innovación vino, al menos, de dos campos distintos: el de la teoría económica y el de las técnicas y metodología (históricas). Ambos contribuyeron vigorosamente a impulsar la investigación con carácter cuantitativo, tal como había sido ya establecida por Posthumus.

Las corrientes de cambio de signo teórico se pusieron claramente de manifiesto en 1954, cuando el primer economista profesional, J. H. van Stuijvenberg, fue elegido para la cátedra de Historia económica de Rotterdam. Siguiendo las huellas de Thurlings en su discurso inaugural, Van Stuijvenberg acentuó el eterno problema económico de la relativa escasez de medios que pueden ser empleados en usos alternativos. Al mismo tiempo señaló los distintos caminos y formas que la humanidad ha utilizado para abordar este problema en el curso de la historia. Aunque Van Stuijvenberg se abstuvo de delinear un programa de investigación, no corría peligro alguno de permanecer aislado. El economista H. Johan de Vries, cuya tesis de 1959 en la Universidad de Amsterdam sobre el declive de la economía holandesa durante el siglo xviII hizo época, fue uno de los primeros que consiguió realizar una brillante obra de análisis histórico tomando como punto de partida algunas teorías generales sobre el crecimiento económico ${ }^{12}$. Cuando, años más tarde, el erudito historiador J. Hovy publicó su estudio, voluminoso y puramente descriptivo, sobre el mismo tema, más o menos, no logró mejorar la obra de De Vries ${ }^{13}$. En un plazo de tiempo sorprendentemente corto, la teoría económica había dominado el campo. Incluso los historiadores económicos que habían sido entrenados profesionalmente como historiadores empezaron a encontrar necesario, o cuanto menos útil, acudir a la economía como campo de referencia. De hecho, tanto los historiadores como los economistas están de acuerdo en cuanto a la aplicación de la teoría económica a la Historia económica se refiere. No hubo polémica alguna enfrentando a ambos grupos de estudiosos, debido, probablemente, a que ambos sectores eran conscientes de las limitaciones y ventajas de la teoría económica.

B. H. Slicher van Bath y su escuela -J. A. Faber, H. K. Roessingh y A. M. van der Woude, especialmente- fueron los principales responsables del otro nuevo enfoque de la Historia económica. Independientemente de la escuela francesa de los Annales, aunque de forma similar, Slicher, que había detentado sucesivamente las cátedras de Groningen, Wageningen, Leiden y Nijmegen, introdujo el estudio de las tendencias a largo plazo a finales de la década de los años cuarenta ${ }^{14}$. Utilizando con métodos cuantitativos todo tipo de información demográfica y económica, intentó, con éxito, elaborar una panorámica general del curso del desarrollo histórico, en especial durante la era

12 Joh. de Vries (1959).

13 J. Hovy (1966).

14 B. H. Slicher van Bath (1945 y 1957). 
preindustrial. La teoría, no obstante, no era su punto fuerte, por lo que, tras una visita de un año al taller del investigador americano más destacado de la Nueva Historia Económica - Robert Fogel, de Chicago-, confesó abiertamente su desilusión. El enfoque de Slicher permaneció siempre fiel al arte de la Historia, hasta el punto de que nunca se contentó con análisis meramente parciales, como el económico, e intentó, por el contrario, dar una visión más completa del desarrollo socioeconómico. Con este fin se esforzó en trabajar en un equipo multidisciplinario al que se unieron diversos especialistas - en Historia, Economía, Sociología, Demografía y Agricultura.

Este enfoque tan amplio es casi imposible de reconciliar con los estudios analíticos del comportamiento pasado de distintos sistemas económicos, lo que, en cierta medida, es siempre el resultado de la teoría económica en abstracto. Algunos investigadores, sin embargo, intentaron combinar lo uno con lo otro. El mejor fue, probablemente, J. A. de Jonge, profesor de la Universidad Libre de Amsterdam, que, lamentablemente, murió muy joven. Entre otras cosas escribió un estudio bastante penetrante sobre la industrialización holandesa durante el siglo xIx, en el que demostró, contra las interpretaciones dominantes, que el crecimiento económico y el desarrollo demográfico se entrelazaron en un proceso de cambio social más o menos equilibrado ${ }^{15}$. P. M. M. Klep, de la Universidad Catćlica de Nijmegen, ha llevado a cabo una investigación similar recientemente sobre el cambio secular a largo plazo en la provincia belga de Brabante, según el cual la sociedad tradicional estaba en vías de transformación hacia la etapa industrial moderna desde la Edad Media ${ }^{16}$.

Todo lo anterior indica claramente que la investigación nacional en Historia económica estaba siguiendo las tendencias y modelos internacionales en lo que se refiere a su base teórica y a la aplicación de métodos y técnicas cuantitativas. Esto se aplica también, hasta cierto punto, a la cuestión de los temas de estudio. La tendencia a concentrar la investigación en el desarrollo económico moderno era manifiesta. Hace algún tiempo, P. H. Winkelman publicó su repaso de unas 150 publicaciones sobre Historia económica que, en su opinión, habían sido de la mayor importancia y categoría durante el último cuarto de siglo ${ }^{17}$. Según este autor, sólo nueve estaban dedicadas a la Historia antigua y medieval, 35 hacían referencia a los siglos xvir y xviII y, al menos, 47 se centraban en el desarrollo econćmico moderno, mientras el resto contenía una mezcla de todo tipo. Obviamente, esta elección temática refleja, al menos parcialmente, la necesidad de los investigadores de proveerse de los instrumentos de la teoría y la información cuantitativa. Ninguno de éstos puede ser utilizado a fondo para estudiar épocas anteriores.

\footnotetext{
is J. A. de Jonge (1968).

16 P. M. M. Klep (1981).

17 Winkelman (1978).
} 
En algunos aspectos, sin embargo, la historiografía económica holandesa ha conservado su naturaleza un tanto provinciana, dado que la investigación se cierne exclusivamente al campo nacional. Los estudios comparativos son relativamente escasos, así como las obras de carácter general o que hacen referencia a otros países.

En resumen, se puede afirmar, no obstante, que durante la década de los años cincuenta y sesenta la Historia económica en los Países Bajos ha alcanzado su madurez. Esto se pone de manifiesto en varios aspectos. Tanto la educación como la investigación vieron un aumento y una expansión sustancial de los conocimientos más avanzados, los cuales recurrían cada vez con mayor frecuencia al uso de una base teórica y de unos métodos cuantitativos. El resultado parece haber sido un alejamiento del saber de la mera descripción de casos individuales, por muy interesantes que éstos pudieran ser, y una mayor inclinación hacia el análisis de las tendencias generales.

\section{Debates y temas de estudio}

Se podría uno preguntar si esta reorganización de la disciplina ha dado lugar a un nuevo entendimiento o comprensión. ¿Cambió de alguna forma concreta la interpretación del curso de la Historia o fue, simplemente, cuestión de detallar los conocimientos ya existentes con sólo añadir nuevos hechos y datos?

Si estoy en lo cierto, los historiadores económicos del último cuarto de siglo han llevado a cabo un cambio conceptual, más o menos fundamental, al menos en tres casos distintos: el ascenso y el declive de la República holandesa en los siglos xviI y xviII; la industrialización del país en el siglo xIX y sus antecedentes; las causas y consecuencias de la Gran Depresión en el siglo xx, y la consiguiente ola de industrialización en el período de la posguerra. Voy a terminar este trabajo intentando resumir brevemente las líneas principales de la discusión en cada uno de estos temas.

Empecemos por la Edad de Oro holandesa y su decadencia. Quizá no sea incorrecto afirmar, simplificando un tanto, que en estos temas el ojo del historiador observó en un principio imágenes de contrastes muy agudos. La economía marítima holandesa, que englobaba todo el mundo, gracias a su arrojada iniciativa, había alcanzado, heroica y milagrosamente, una etapa de espléndida prosperidad comercial en el siglo xvir. Todo esto se perdió, no obstante, durante el siglo xvin, bien por la acre rivalidad de otras potencias extranjeras que estaban en ascenso, bien por la pérdida de energía y decisión entre la clase gobernante.

De Vries demostró convincentemente en 1959 que, no obstante, la así lla- 
mada decadencia económica del siglo xviri había sido un fenómeno muy relativo ${ }^{18}$. Este mismo autor llevó el argumento más allá, poniendo énfasis en la continuidad de la vida económica en el período preindustrial. En su opinión, los mismos factores de desarrollo fueron los responsables del crecimiento preindustrial y de su posterior despegue. Frente a las opiniones establecidas, De Vries mantuvo en particular que la formación de capital y de las finanzas, lejos de ser responsables de la decadencia, en realidad la retrasaron ${ }^{19}$. Slicher, Faber ${ }^{20}$, Van der Woude ${ }^{21}$ y el investigador norteamericano Jan de Vries ${ }^{22}$ demostraron las diferencias y variaciones regionales de la economía, llamando especialmente la atención sobre el papel decisivo, pero un tanto olvidado, de la agricultura como factor de desarrollo económico. La interacción de los mercados agrícolas y urbanos desde los comienzos del siglo xvi se demostró que había sido crucial. Algunas de las opiniones antiguas se vieron, sin embargo, confirmadas en cierta medida por los penetrantes estudios cuantitativos sobre las relaciones comerciales de Holanda y los países bálticos del historiador suecoholandés Th. Lindblad ${ }^{23}$ y F. Snapper, junto con el canadiense Jake Knoppers ${ }^{24}$. Por otra parte, el inglés Jonathan Israel ha mantenido, basándose en un cuerpo de información muy detallado, que el comercio hispano-holandés ha sido infravalorado en gran medida ${ }^{25}$. En cualquier caso, cada vez está más claro que el caso holandés encaja perfectamente en el modelo de desarrollo económico preindustrial, por lo que su singularidad ha sido puesta en duda. Hoy día, apenas queda nada de aquella imagen del repentino milagro holandés que se malogró de alguna forma. Permanece, sin embargo, una imagen más compleja y variada de un lento proceso de desarrollo económico diferenciado, moldeado según los cambios de la economía mundial preindustrial.

Pasemos ahora al desarrollo de la economía holandesa durante el siglo xIx. A excepción de la obra clásica de I. J. Brugmans, que ya había aparecido en 1925, los historiadores económicos no prestaron atención a este tema hasta después de la Segunda Guerra Mundial ${ }^{20}$. Las ideas dominantes se limitaron a situar el caso holandés en un marco de referencia que se basaba en la Revolución Industrial inglesa. Bajo este enfoque, el comportamiento holandés fue más bien pobre. El estancamiento y la decadencia frenaron a la economía hasta mediados de siglo y, a partir de entonces, el capitalismo industrial tan sólo avanzó con gran lentitud. A consecuencia de ello, el crecimiento económico

1" Joh. de Vries (1959).

19 P. W. Klein (1977 y 1978).

${ }^{20} \mathrm{~J}$. A. Faber (1972).

21 A. M. van der Woude (1972).

22 J. de Vries (1974).

${ }^{23}$ J. Th. Lindblad (1982).

24 J. V. T. Knoppers/F. Snapper (1978).

25 Jonathan I. Istael (1982).

26 I. J. Brugmans (1925). 
también avanzó despacio y de forma dubitativa, y la empresa permaneció anticuada e ineficiente. ¿Qué o quién tuvo la culpa?

La discusión de este problema se inició en el período de la posguerra, a través del debate instigado por J. G. van Dillen y W. J. Wieringa, el primero de ellos señalando a las circunstancias, y el segundo criticando especialmente la psicología y las actitudes mentales de la población ${ }^{27}$. El debate nunca llegó a su fin y sigue hoy adelante. Probablemente continúe en tanto que no se presenten hipótesis que puedan ser verificadas. Pero esto no quiere decir que no haya producido algunos frutos. Al contrario, ya en los años sesenta se plantearon nuevos aspectos y dimensiones del problema. H. F. J. M. van den Eerenbeemt fue el primero en descubrir que la empresa industrial podía jactarse de importantes innovaciones bastante antes de mediados de siglo ${ }^{28}$. Este mismo autor propagó la idea de que la empresa tradicional realmente abrió el camino hacia la modernización y la industrialización durante la segunda mitad del siglo xix ${ }^{29}$. La tesis doctoral de J. A. de Jonge, sin embargo, dio pie a una investigación innovadora en $1968^{30}$. Su propio trabajo había sido un análisis admirable del crecimiento equilibrado de los Países Bajos durante el período del take-off de su industria manufacturera moderna entre 1890 y 1910 . Ahora bien, De Jonge explicaba el cómo de este proceso, pero no el porqué.

Una vez más, la discusión se orientó a explicar el atraso en la mecanización de la industria. El mismo De Jonge no creía en ninguna respuesta estándar, y en otra publicación sugirió que las imperfecciones del sistema de transporte eran responsables de las grandes diferencias de desarrollo entre las distintas regiones ${ }^{31}$. El historiador norteamericano Joel Mokyr ofreció una respuesta bien clara. Basándose fundamentalmente en razones teóricas, hizo responsable del retraso a las discrepancias entre salarios elevados, por una parte, y tasas de beneficio bajas, por otra ${ }^{32}$. Sin embargo, R. W. J. M. Bos criticó, no sin razón, este enfoque global del problema, y llamó la atención sobre los efectos de las diferencias estructurales en el coste relativo de producción (capital, trabajo y recursos naturales) y sobre las barreras infraestructurales en la red de relaciones interregionales ${ }^{33}$. De nuevo quedó claro que no puede haber un solo factor o un grupo aislado de factores responsable del atraso. Este tipo de razonamiento ha llevado recientemente a la sorprendente afirmación de que, para empezar, nunca hubo un verdadero retraso. R. T. Griffiths y J. J. M. de Meere, de la Universidad Libre de Amsterdam, sugieren que la

$\therefore$ J. G. van Dillen (1949); W. J. Wieringa (1955).

2* H. F. I. M. van den Eerenbeemt (1965).

${ }^{24}$ P. W. Klein (1966 y 1973).

${ }^{30} \mathrm{~J}$. A. de Jonge (1968).

"J. A. de Jonge (1971).

'2. Mokyr (1974).

${ }^{3}$ R. W. J. M. Bos (1977 y 1979). 
economía holandesa prosperó, de hecho, desde aproximadamente la década de los años veinte, con tan sólo movilizar sus recursos agrarios al máximo ${ }^{34}$. Además, E. J. Fischer ha mostrado recientemente que un crecimiento económico máximo podía darse, incluso en la industria manufacturera, sin mecanización alguna de la producción ${ }^{35}$.

De nuevo parece que los Países Bajos no fueron la excepción única y peculiar que habían creído generaciones anteriores de historiadores. Su economía estaba simplemente adaptándose de forma bastante flexible a las oportunidades y posibilidades de su entorno.

Lo mismo se aplica a los cambios en la interpretación del desarrollo de la economía holandesa desde el período de entreguerras ${ }^{36}$. Hasta los primeros años setenta se mantuvo, generalmente, que la economía holandesa había sido especialmente afectada por la depresión de los años treinta. Se pensaba que la depresión había sido mucho más profunda que en países vecinos, los cuales, por otra parte, habían sido capaces de librarse de sus paralizadores efectos mucho antes. Las razones que se alegaban por esta excepcional mala suerte no estaban muy lejos: principalmente habían sido las medidas y la política económica equivocadas, dado que el Gobierno actuó alocadamente, persiguiendo fines completamente contradictorios. Manteniendo sus principios estrictamente liberales a favor del libre comercio, intentó mejorar las exportaciones holandesas mediante extremas medidas de austeridad, como cortes del presupuesto y reducción de los salarios. Pero esta política tropezó con la lucha por mantener el valor del guilder, las medidas de carácter social y los subsidios a la agricultura y a otros sectores en conflicto. Según esta interpretación, Holanda no supo comprender la realidad del mundo, probablemente porque se había salvado de los horrores de la Primera Guerra Mundial. Si se hubieran entendido esas realidades, se hubiera podido hacer frente a la situación adecuadamente. Sin embargo, durante los años setenta se puso de manifiesto que la política económica holandesa era sólo parcialmente responsable ${ }^{37}$. En realidad, no se había apartado demasiado del curso seguido por otros paises. Si fuera cierto que la depresión se había hecho sentir más duramente en los Países Bajos que en cualquier otro lugar, esto se debió, probablemente, a la estructura específica de sus sectores productivos. A consecuencia de elasticidades de renta desfavorables, la producción de la moderna manufactura holandesa se encontró con dificultades particulares en el mercado mundial. Lo mismo sucedió en sectores importantes de la agricultura y la navegación.

Según P. E. de Hen, está fuera de lugar el acusar al Gobierno holandés

${ }^{34}$ R. T. Griffiths (1980); J. J. M. de Meere (1982).

${ }^{35}$ E. J. Fischer (1983).

36 Joh. de Vries (1978).

${ }^{37}$ P. W. Klein (1975). 
de los años treinta de abandono o inactividad, dado que, de hecho, favoreció la implantación de las medidas de industrialización que resultaron ser tan beneficiosas después de la Segunda Guerra Mundial ${ }^{38}$. La rápida recuperación de la economía de los severos daños de la guerra y el posterior período de crecimiento elevado continuo, que duró hasta comienzos de los años setenta, dio lugar, una vez más, a que se hablara del milagro holandés. Más de un escritor comparó este proceso con el período de preguerra, acentuando la sorprendente y excepcional armonía que súbitamente había aparecido entre Gobierno, trabajo y capital ${ }^{39}$. Con toda seguridad, éste podría ser considerado el principal factor responsable de un crecimiento sin obstáculos. Hasta ahora, los historiadores económicos no han prestado excesiva atención al fenómeno del crecimiento durante los años cincuenta y sesenta. Su principal preocupación siguió siendo la recuperación inmediata a la posguerra, entre 1945 y $1950^{40}$ Aun así, sus escritos acentúan la continuidad de las experiencias de la preguerra, y no han sacado a la luz ningún nuevo milagro. Lo que sí señalan es una política bien escogida y unas condiciones y circunstancias favorables. De hecho, también el resto del mundo occidental estaba prosperando, y los holandeses no se apartaron realmente de este modelo.

No parece arriesgado profetizar que pronto se descubrirá que la Historia económica holandesa puede siempre regresar a la tendencia normal. Holanda no es diferente.

(Traducido por Clara Eugenia Núñez.)

${ }^{38}$ P. E. de Hen (1980).

${ }^{39}$ J. P. Windmuller (1969).

to La excepción es: R. T. Griffiths (1980). Véanse también: P. Fortuyn (1980); P. W. Klein/G. N. van der Plaat (1981). 


\section{BIBLIOGRAFIA}

Alberts, W. Jappe/JAnSEN, H. P. H. (1964): Welvaart in Wording. Sociaal-economische geschiedenis van Nederland van de vroegste tijden tot het einde der Middeleeuwen. Algemene geschiedenis der Nederlanden. Middeleeuwen, vols. I-IV, 1980, 1981, 1982.

BAASCH, E.: Holländische Wirtschaftsgeschichte, 1927.

BAudet, H./Meulen, H. van der (eds.) (1978): Kernproblemen der economische geschicdenis.

Bos, R. W. J. M. (1977): «Van Periferie naar centrum; enige kanttekeningen bij de Nederlandse industriële ontwikkeling in de negentiende eeuw», en GEERTS/MESSING, vol. II.

Bos, R. W. J. M. (1979): «Factorprijzen, technologie en marktstructuur; de groei van de Nederlandse volkshuishouding 1815-1914», en A. A. G. BIJdRAGEN (22).

Bos, Th. S. H.: Repertorium van boeken en tijdschriftartikelen betreffende de geschiede. nis van Nederland verschenen in 1979, 1980, 1981, $1982(1981,1982,1983,1984)$.

BRugmans, I. J. (1925): De arbeidende klasse in Nederland in de 19 eeuw (1813-1870).

DILleN, J. G. van (1914): Het economisch karakter van de Middeleeuwse stad.

Dillen, J. G. van (1949): Omstandigheden en psychische factoren in de economische gescbiedenis van Nederland.

Eerenbeemt, H. F. J. M. van den (1965): Bedriftskapitaal en ondernemersschap.

FABER, J. A. (1972): Drie eeuwen Friesland. Economische en sociale ontwikkelingen van $1500-1800$.

FISC HER, E. J. (1983): Fabriqueurs en Fabrikanten.

Fortuyn, P. (1980): Sociaal economische politiek in Nederland 1945-1949.

Geerts, P. A. M./Messing, F. A. M. (1977): Economische ontwikkeling en sociale emancipatie, vols. I y II.

GRIFFITHS, R. T. (1979): Industrial retardation in the Netberlands 1830-1850.

GrIfFITHS, R. T. (1980): Acbter, acblerlijk of anders; aspecten van de economiscbe ontwikkeling van Nederland in de $19^{\circ}$ eeuw.

GriffithS, R. T. (ed.) (1980): The economy and politics of the Netherlands since 1945.

HEN, P. E. de (1980): Actieve en re-actieve industriepolitiek in Nederland.

Houtre, J. A. van (1977): An economic bistory of the Low Countries 800-1800, Londres.

Hovy, J. (1966): Het voorstel van 1751 tot instelling van een beperkt vrijhavenstelsel in de Republiek.

IsRAEL, Jonathan I. (1982): The Dutch Republic and the Hispanic World 1606-1661.

JONGE, J. A. de (1968): De industrialisatie in Nederland tussen 1850 en 1914.

Jonge, J. A. de (1971): «The role of the Outer-Provinces in the process of Dutch economic growth in the nineteenth century», en Britain and the Netberlands IV.

KLEIN, P. W. (1966): Traditionele ondernemers en economische groei in Nederland $1850-1914$.

KLEIN, P. W. (1970): Van stapelmarkt tot welvaarstsstaat (appendix).

KLEIN, P. W. (1973): «Het bankwezen en de modernisering van de Nederlandse volkshuishouding tijdens de tweede helft van de $19^{\circ}$ eeuw», en Economisch-en SociaalHistorisch Jaarboek (36).

KLEIN, P. W. (1975): «Depression and policies in the thirties», en Acta Historiae Neerlandicae (VIII).

KLEIN, P. W. (1977): “Kapitaal en stagnatie tijdens het Hollandse vroegkapitalisme», en P. A. M. GeERTs/F. A. M. Messing, vol. I.

KLEIN, P. W. (1978): «De zeventiende eeuwm, en VAN Stuyvenberg (ed.).

Klein, P. W./Plant, G. N. van der (eds.) (1981): Herrijzend Nederland, Opsiellen over Nederland in de periode 1945-1950.

KLEP, P. M. M. (1981): Bevolking en arbeid in transformatie. Een onderzoek in Bra. bant 1700-1900. 
Knoppers, J. V. T./Snapper, F. (1978): «De Nederlandse scheepvaart op de Oostzee vanaf het einde van de zeventiende eeuw tot het begin van de negentiende eeuw". en Economisch-en Sociaal-Historisch Jaarboek (41).

LindBlad, J. Th. (1982): Sueden: trade with the Dutch Republic 1738-1795.

MeEre, J. J. M. de (1982): Economische ontwikkeling en levensstandaurd in Nederland gedurende de eerste belft van de negentiende eeuw.

MujnaAdT, W. W. (ed.) (1983): Kantelend gescbiedbeeld. Nederlandse bistoriografic sinds 1945.

MoKYR, J. (1974): Industrial growth and stagnation in the Low Countries.

Post humus, N. W. (1908): De geschiedenis van de Leidse lakenindustrie.

Slicher van Bath, B. H. (1945): Mensch en land in de Middeleeuwen, 2 vols.

SLICHER vaN BATH, B. H. (1957): Een samenleving onder spanning. Geschiedenis van bet platteland in Overijssel.

SLICHER VAN BATH, B. H. (1965): "The economic and social conditions in the Frisian districts from 900-1500\%, en A. A. G. BIjDRAGEN (13).

Slicher van Bat H, B. H. (1967): "Theorie en praktijk in de economische en sociale geschiedenis», en A. A. G. BijDRAGEN (14).

STUYVENBERG, I. H. van (ed.) (1978): De economische geschiedenis van Nederland.

SNELLER, Z. W. (1916): Walcheren in de viftiende eeuu.

Thurlings, Th. L. M. (1947): «De taak en betekenis der moderne economische geschiedenis», en De Economist (95).

Uytven, R. van (1978): "Oudheid en Middeleeuwen», en J. H. van Stuyvenberg (ed.).

VRIES, Jan de (1974): The Dutch rural economy in the Golden Age 1500-1700.

VRIES, Johan de (1959): De economische achieruitgang der Republiek in de achitiende eeuw.

VRIES, Johan de (1978): The netberlands economy in the twentieth century.

WIERINGA, W. I. (1955): Economische beroriënlering in Nederland in de 19 ceuw.

Wieringa, W. J. (1978): "De beoefening der economische geschiedenis in Nederland". en Baudet/Van der Meulen (eds.).

WINDMULLER, J. P. (1969): Labor relations in the Netherlands.

Winkelman, P. H. (1978): "De introductie van de economische en sociale geschiedenis en Nederland», en H. Baudet/H. van dFr Meulen (eds.).

Woude, A. M. van der (1972): Het Noorderkwartier. Fen r'gional-historisch onderzock in de demografische en economiscbe gescbiedenis van Westeliik Nederland. 